\title{
Unusual Location of a Second Mesiobuccal Canal in the Maxillary First Molar managed with the Aid of Cone-beam Computed Tomography
}

\author{
${ }^{1} \mathrm{R}$ Randhya, ${ }^{2}$ Sathish Sundar, ${ }^{3}$ Dinesh Kowsky, ${ }^{4} \mathrm{~N}$ Velmurugan, ${ }^{5}$ Buvaneshwari Arul
}

\begin{abstract}
Introduction: The purpose of this article was to emphasize the importance of understanding root canal anatomy and its variations for successful endodontic treatment.

Methods: This case report presents the detection and endodontic management of eccentrically placed second mesiobuccal (MB) canal in maxillary first molar with the help of dental operating microscope and cone-beam computed tomography (CBCT) scanning.
\end{abstract}

Results: Cone-beam computed tomography images showed broad MB root with second MB canal located closer to palatal orifice.

Conclusion: This report describes a variation in canal location and complex anatomy of maxillary first molar with posttreatment apical periodontitis which was managed successfully with the aid of dental operating microscope and CBCT.

Keywords: Cone-beam computed tomography, Maxillary first molar, Second mesiobuccal canal.

How to cite this article: Randhya R, Sundar S, Kowsky D, Velmurugan N, Arul B. Unusual Location of a Second Mesiobuccal Canal in the Maxillary First Molar managed with the Aid of Cone-beam Computed Tomography. J Oper Dent Endod 2016;1(1):35-38

Source of support: Nil

Conflict of interest: None

\section{INTRODUCTION}

Knowledge about normal root canal anatomy and its aberrations is essential to achieve success in endodontics. ${ }^{1}$

Maxillary first molar usually have three roots and four root canals and are one of the most commonly treated teeth in endodontics.

\footnotetext{
1,5 Postgraduate Student, ${ }^{2,3}$ Senior Lecturer

${ }^{4}$ Professor and Head

${ }^{1-5}$ Department of Conservative Dentistry and Endodontics Meenakshi Ammal Dental College and Hospital, Chennai Tamil Nadu, India

Corresponding Author: Dinesh Kowsky, Senior Lecturer Department of Conservative Dentistry and Endodontics Meenakshi Ammal Dental College and Hospital, Chennai Tamil Nadu, India, Phone: 8754205767, e-mail: kowskydinesh@ gmail.com
}

A wide variation of root and canal configurations of the maxillary first molar has been documented in dental literature from single root canal in single root ${ }^{2}$ two root canals, ${ }^{3}$ five root canals, ${ }^{4}$ six root canals, ${ }^{5}$ seven root canals $^{6}$ and a maximum of eight root canals. ${ }^{7}$

Maxillary molars are known to have an additional second mesiobuccal (MB2) canal in the MB root. The reported incidence of MB2 detected using the dental operating microscope is more than $95 \% .{ }^{8,9}$

Failure to locate and treat an existing MB2 canal could decrease the long-term prognosis of the tooth. Both in vitro investigations and clinical studies have shown that the use of specialized ultrasonic tips and dental operating microscope increases the rate of detection and negotiation of the MB2 canal. ${ }^{2,10}$

Newer diagnostic tools, such as cone-beam computed tomography (CBCT), have been shown to be very useful in studying complex root canal anatomy by providing a three-dimensional view of the involved tooth. ${ }^{11-13}$

The present case report describes the successful endodontic management of maxillary first molar with an unusual location of the MB2 canal which was located closer to the palatal orifice.

\section{CASE REPORT}

A 23-year-old male patient reported to the Department of Conservative Dentistry and Endodontics with a chief complaint of mild but continuous pain in the upper right back tooth region for the past 3 weeks. The patient gave a history of root canal treatment performed 2 months ago elsewhere. Mild pain persisted even after the treatment. The patient also complained of episodes of sensitivity to hot and cold in the involved tooth. The intensity of pain had increased for the past 1 week.

Upon intraoral examination, a coronal access restoration was seen on the maxillary right first molar and the tooth was tender on percussion. The periodontal pocket and mobility were within the physiological limits.

Preoperative periapical radiograph showed radiopaque fillings in three roots (Fig. 1A). There were no signs of periapical radiolucency and no widening of lamina dura in the radiograph. The radiograph also showed an unusual radicular outline on the mesial aspect suggestive of an additional root. Based on the clinical 
and radiographic examination, the tooth was diagnosed to have post-treatment apical periodontitis. Endodontic retreatment was suggested, for which the patient consented.

After administration of a local anesthetic (Lignox 2\%, Indoco Remedies Ltd., Mumbai, India), access was re-entered under rubber dam isolation. The coronal restoration was removed and all the orifices were observed under dental operating microscope at $8 \times$ magnification (Revelation Seiler Precision Microscope, Inc, USA) - three orifices [one palatal, one MB and one distobuccal (DB) orifice] were located and identified.

An attempt to find MB2 in its usual location using ultrasonic tips ET40 (Satelec/Acteon, Merignac, France) under magnification turned out to be unsuccessful. But on exploring the floor of the pulp chamber with a DG-16 explorer under dental operating microscope, a distinct catch was felt buccal to the palatal orifice. A size $10 \mathrm{~K}$-file was used to confirm the patency of the canal. Since the orifice was located very close to the palatal orifice, it was presumed to be a second palatal canal orifice. Previously, filled gutta-percha (GP) from other canals was removed using a GP solvent (RC Solve, Prime Dental Products Pvt
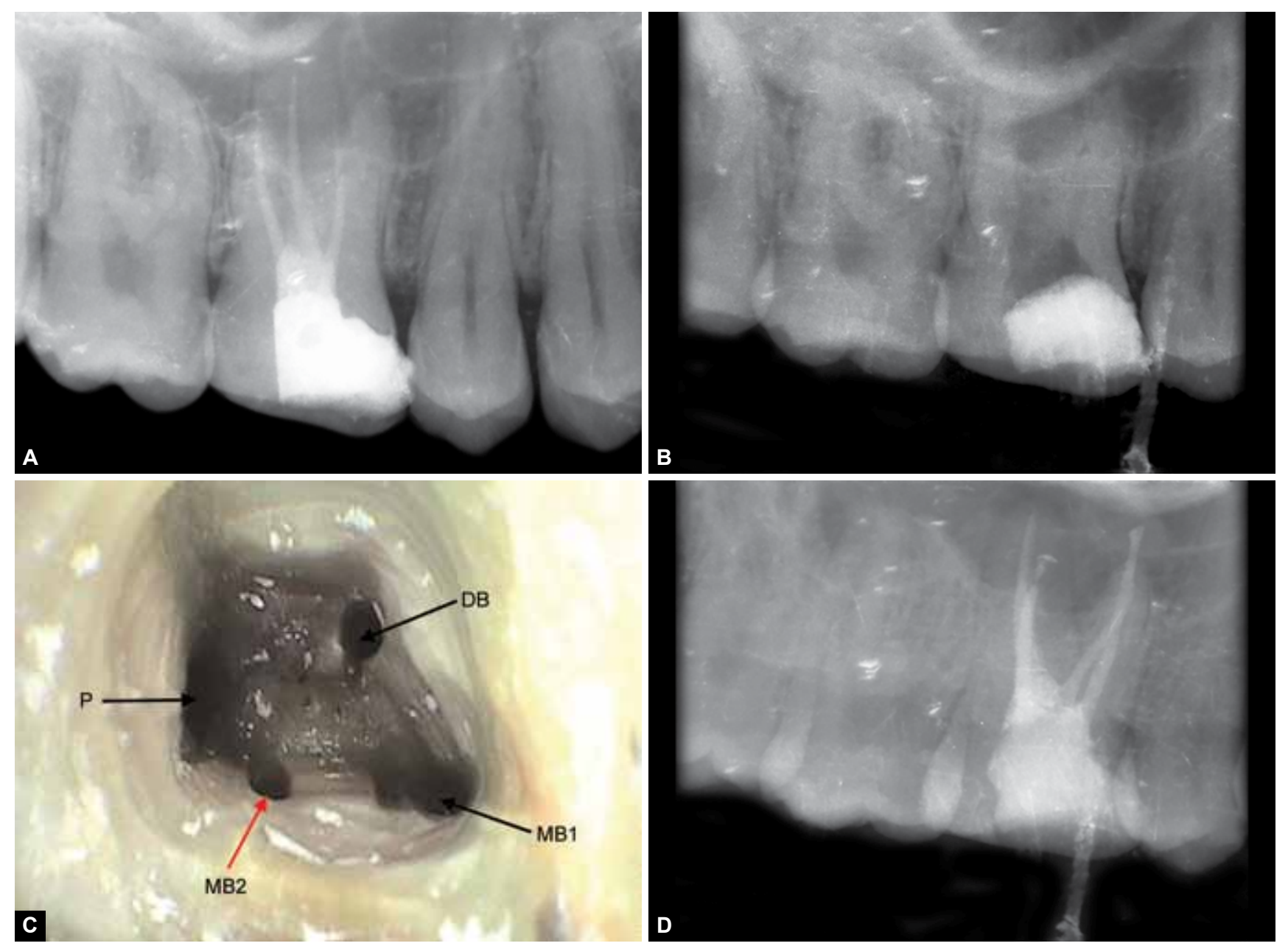

Figs 1A to D: (A) Preoperative radiograph, (B) intraoral periapical radiograph after gutta-percha removal, (C) pulpal floor under dental operating microscope (magnification: $8 x$ ) and (D) postobturation radiograph

Ltd., Thane, India) (Fig. 1B) and Protaper retreatment files (Dentsply Maillefer, Switzerland). Working length of each canal was re-established using an apex locator and was verified radiographically.

Since the extracanal orifice was detected in an unusual location (Fig. 1C), a limited $4 \times 4 \mathrm{~cm}$ field of view CBCT was taken to understand canal anatomy better. Conebeam computed tomography revealed the extracanal that was identified closer to the main palatal orifice to be actually the second MB canal. Both the MBs had a separate portal of exit.

The canals were then cleaned and shaped in a crowndown sequence using rotary NiTi ProTaper Universal file system (Dentsply Maillefer, Switzerland). First mesiobuccal (MB1) and MB2 canals were prepared to F2 size and DB and palatal canals were prepared to size F3. A total of $2.5 \%$ sodium hypochlorite was used as the primary irrigant during cleaning and shaping. Following canal preparation, 17\% EDTA was used to remove the smear layer and $2 \%$ chlorhexidine was used as a final flush. The canals were then dried using sterile absorbent paper points and obturated with GP and AH plus sealer using cold lateral compaction technique. The$$
\text { (D) postobturation radiograph }
$$ 
access cavity was then restored with a resin composite (Fig. 1D). Patient was asymptomatic during the follow-up period of 6 months.

Mesiobuccal root of the maxillary first molar is one of the most frequently studied roots both in vitro and in vivo. ${ }^{14}$ Access cavity modification under proper illumination and magnifications can aid in better detection of the MB2 canal. ${ }^{2}$ A few authors suggested other methods like the bubble test, methylene blue dyes, troughing with ultrasonics, etc. for identifying extra canals. ${ }^{15}$ The MB2 canal is usually located on the line joining the MB1 and palatal canal closer to MB1. ${ }^{15}$ In more than $54 \%$ of the cases, the MB2 canal joins the MB1 canal and has a single portal of exit. ${ }^{16}$ The chances for locating MB2 decrease as the age increases. ${ }^{17,18}$

In case of extrapalatal canals, it is mostly located on the mesial or distal aspect of the root, never on buccal or lingual. Recently, Kottoor et al reported the presence of MB2 canal between MB1 and DB1 in a seven-canalled maxillary first molar. ${ }^{6}$ The same author also reported the presence of three MB canals in the maxillary first molar with eight canals. ${ }^{7}$

\begin{tabular}{lll}
\hline \multicolumn{3}{c}{ Review on unusual location of MB2 canal } \\
\hline Investigators $^{1}$ & Years & Location \\
\hline Kottoor J et al $^{6}$ & 2010 & $\begin{array}{l}\text { MB2 was located in } \\
\text { between MB1 and DB1 in } \\
\text { the maxillary first molar }\end{array}$ \\
Faramarzi F et al ${ }^{19}$ & 2015 & $\begin{array}{l}\text { Highest distance between } \\
\text { MB1 and MB2 was 4 mm } \\
\text { and lowest was 1.5 mm }\end{array}$ \\
$\begin{array}{l}\text { Chakradhar Raju } \\
\text { et al }{ }^{20}\end{array}$ & 2010 & $\begin{array}{l}\text { MB2 was located very close } \\
\text { to the palatal orifice and } \\
\text { presumed to be a second } \\
\text { palatal orifice }\end{array}$ \\
\hline
\end{tabular}

Cone-beam computed tomography has been used previously to understand complex root canal anatomy. ${ }^{8}$ In the present case, the CBCT confirmed the presence of MB2 canal closer to the palatal canal. It also revealed the $\mathrm{MB}$ root to be broader buccolingually and tilted mesially. This could probably result in the eccentric position of MB2. This case report has indicated the search for MB2 should be done closer to the palatal canal also. In our case, distance between MB1 and MB2 at three different levels was estimated using CBCT: cervical level-5.607 mm (Fig. 2A), middle level-5.317 mm (Fig. 2B) and apical level-4.772 mm (Fig. 2C).

The usual distance between MB1 and MB2 ranges from 1.5 to $2 \mathrm{~mm}$ mesially and 2.5 to $3.5 \mathrm{~mm}$ palatally with a maximum reported distance of $4 \mathrm{~mm}$ by Faramarzi et al. ${ }^{19}$ Here, the MB2 canal was located $5.607 \mathrm{~mm}$ away from the MB1 canal at the orifice level. Raju et al reported an unusual case of MB2 orifice located closer to the palatal orifice, but they have not mentioned the distance between MB1 and MB2 canals. ${ }^{20}$ Post-treatment apical periodontitis in this case could be related to the unidentified and nontreated MB2 canal. Diligent search using magnification and ultrasonic tips could increase the probability of finding and treating such eccentrically placed canals. The clinician must be aware about such unusual location of MB2 and hence search must be made even closer to the palatal orifice, if MB2 is not identified in its usual location.

\section{CONCLUSION}

The current case report describes the unusual location of a second MB canal found close to the palatal orifice in a maxillary right first molar, which was managed with the help of dental operating microscope and CBCT.
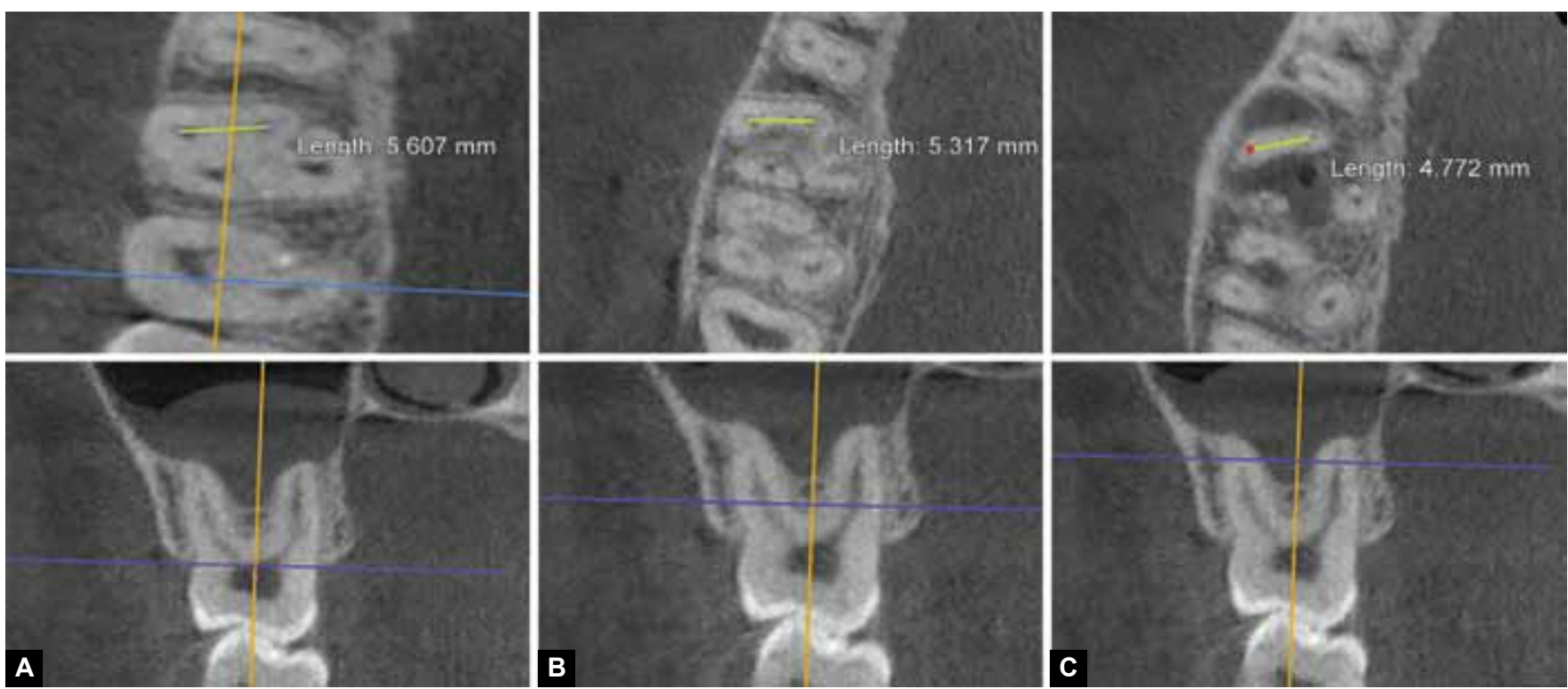

Figs 2A to C: (A) Cone-beam computed tomography image at cervical level, (B) CBCT image at middle level and (C) CBCT image at apical level 


\section{REFERENCES}

1. Degerness RA, Bowles WR. Dimension, anatomy and morphology of the mesiobuccal root canal system in maxillary molars. J Endod 2010;36(6):985-989.

2. Gopikrishna V, Bhargavi N, Kandaswamy D. Endodontic management of maxillary first molar with as single root and single canal diagnosed with the aid of spiral CT: a case report. J Endod 2006;32(7):687-691.

3. Malagnino V, Gallottini L, Passariello P. Some unusual clinical cases on root anatomy of permanent maxillary molars. J Endod 1997 Feb;23(2):127-128.

4. Beatty RG. A five canal maxillary first molar. J Endod 1984 Apr;10(4):156-157.

5. Karthikeyan K, Mahalaxmi S. New nomenclature for extra canals based on four reported cases of maxillary first molars with six canals. J Endod 2010;36(6):1073-1078.

6. Kottoor J, Velmurugan N, Sudha R, Hemamalathi S. Maxillary first molar with seven root canals diagnosed with cone-beam computed tomography scanning: a case report. J Endod 2010 May;36(5):915-921.

7. Kottoor J, Velmurugan N, Surendran S. Endodontic management of a maxillary first molar with eight root canal systems evaluated using cone-beam computed tomography scanning: a case report. J Endod 2011;37(5):715-719.

8. Buhrley LJ, Barrows MJ, BeGole EA, Wenckus CS. Effect of magnification on locating the MB2 canal in maxillary molars. J Endod 2002;28(4):324-327.

9. Kulild JC, Peters DD. Incidence and configuration of canal systems in the mesiobuccal root of maxillary first and second molars. J Endod 1990 Jul;16(7):311-317.

10. Iqbal MK. Non surgical ultrasonic endodontic instruments. Dent Clin North Am 2004 Jan;48(1):19-34.

11. Mirmohammadi H, Mahdi L, Partovi P, Shemesh H, Hassan B. Accuracy of cone-beam computed tomography in the detection of a second mesiobuccal root canal in endodontically treated teeth: an ex-vivo study. J Endod 2015;41(10): 1678-1681.

12. Silva EJ, Nejaim Y, Silva AV, Haiter-Neto F, Cohenca N. Evaluation of root canal configuration of mandibular molars in a brazilian population by using cone-beam computed tomography: An in vivo Study. J Endod 2013;39(7):849-852.

13. Neelakantan P, Subbarao C, Ahuja R, Subbarao CV, Gutmann JL. Cone-beam computed tomography study of root and canal morphology of maxillary first and second molars in an Indian population. J Endod 2010;36(10):1622-1627.

14. Hasan M, Khan FR. Diagnosis of second mesiobuccal canal in maxillary first molars among patients visiting a tertiary care hospital. Int J Biomed Sci 2015;11(2):107-108.

15. Frank J, Vertucci, James E. Haddix. Tooth morpholoy and Access cavity preparation. In: Cohen S, Burns RC, editors. Pathways of the Pulp. 10th ed. St. Louis: Mosby Year Book; 2010. p. 136-222.

16. Das S, Warhadpande MM, Redij SA, Jibhkate NG, Sabir H. Frequency of second mesiobuccal canal in permanent maxillary first molars using the operating microscope and selective dentin removal: a clinical study. Contemp Clin Dent 2015;6(1):74-78.

17. Fogel HM, Peikoff MD, Christie WH. Canal configuration in the mesiobuccal root of the maxillary first molar: a clinical study. J Endod 1994 Mar;20(3):135-137.

18. Al Shalabi RM, Omer OE, Glennon J, Jennings M, Claffey NM. Root canal anatomy of maxillary first and second permanent molars. Int Endod J 2000;33(5):405-414.

19. Faramarzi F, Vossoghi M, Shokri A, Shams B, Vossoghi M, Khoshbin E. Cone-beam computed tomography study of root and canal morphology of maxillary first molar in an Iranian population. Avicenna J Dent Res 2015;7(1):e24088.

20. Chakradhar Raju RV,SatheN,Morisetty PK, VeeramachaneniC. Endodontic management of a maxillary first molar with unusual location of second mesiobuccal orifice. J Conserv Dent 2010 Jul-Sep;13(3):162-164. 